\title{
Preprints na Área da Saúde
}

\author{
Rodrigo Daminello Raimundo ${ }^{1}$
}

'Laboratório de Delineamento de Estudos e Escrita Científica, Centro Universitário Saúde ABC (FMABC) - Santo André (SP), Brasil. E-mail: rodrigo.raimundo @ fmabc.br

DOI: https://dx.doi.org/10.7322/abcshs.v44i3.1397

Avanços tecnológicos trouxeram melhor comunicação, integração, organização, eficiência e produtividade para a humanidade e, consequentemente, para a área da saúde. Publicações em periódicos científicos necessitam de revisões por pares (peer-review), que é um dos processos mais complicados, e muitas vezes mais demorados, para a edição de jornais científicos. Dessa forma, tem crescido a aceitação dos chamados preprints (eprint ou e-imprime ou working papers) na tentativa de agilizar a comunicação e divulgação dos manuscritos ${ }^{1,2}$.

Preprint ou "pré-impressão" é um manuscrito científico completo que é disponibilizado online antes da sua aceitação e publicação oficial por um jornal científico. Em outras palavras, é o texto completo do trabalho de pesquisa enviado pelos autores ao periódico científico que é compartilhado publicamente antes da avaliação pelos revisores ${ }^{3,4,5}$. O principal destino dos preprints são repositórios, coleção de documentos digitais colocados em um servidor público para compartilhar metadados. Na sua grande maioria os preprints recebem um identificador de objeto digital (DOI) - padrão de letras e números que serve para identificar itens digitais tornando os arquivos na internet permanentes ${ }^{6,7}$.

Repositórios como o arXiv.org (muito usado por matemáticos e físicos) costumam avaliar rapidamente (às vezes menos de 24 horas) o manuscrito para confirmar que é de conteúdo científico. Após a confirmação, o preprint é colocado no site e qualquer pessoa pode acessar, visualizar, comentar e colaborar. Sem dúvida, a agilidade da disseminação torna o manuscrito com maior visibilidade e acessibilidade. Em contrapartida, são textos que não passaram pela revisão sofisticada dos especialistas sendo mais passíveis de erros. Atualmente além do citado arXiv.org, podemos destacar: bioRxiv, F1000Research, PeerJPreprints, ChemRxiv entre outros ${ }^{5,6}$.

Em janeiro de 2018, Serghiou e Loannidis ${ }^{7}$ publicaram no consagrado JAMA um estudo que analisou todos os preprints depositados no repositório bioRxiv entre 2013 e 2017. Pela análise Altmetric (método alternativo para valorização de citações de pesquisa voltadas para um público mais amplo) e do CrossRef os artigos que foram depositados inicialmente como preprints mostraram melhor visibilidade que artigos que não foram depositados como preprints.

O uso de "pré-impressões" não é novo, existem relatos que o National Institutes of Health já em 1961 enviava manuscritos pelo correio antes do peer-review. Alguns pesquisadores ainda têm muito receio dos preprints justamente pelos estudos não terem sido avaliados por especialistas ${ }^{2,3,4}$. Existe também a preocupação do "roubo" das ideias antes da publicação (conhecido como scooping). Nesta questão, deve-se lembrar que pesquisadores e cientistas divulgam suas ideias em palestras e apresentações em congressos. Além disso, os repositórios publicam as datas dos posts do manuscrito podendo o autor reivindicar a autoria. Finalmente, a publicação do preprint é uma oportunidade para apontar falhas e fortalecer argumentos para melhoria do artigo final ${ }^{5,6,7}$.

Para os cientistas que não acreditam que os preprints podem dominar as publicações em breve, deve se lembrar no crescimento do movimento Open Science (Ciência Aberta) ${ }^{8}$. Este movimento pretende tornar a pesquisa científica mais acessível para todos os níveis da sociedade - não apenas para cientistas. Jornais consagrados como a Nature e Plos One já permitem submissão de manuscritos que estavam publicados como preprint. Deve-se lembrar que o movimento "Ciência Aberta" tem como característica a contribuição para facilitar a resolução de problemas, disponibilizar dados e permitir que estas informações sejam reutilizadas. "Ciência Aberta" e preprints têm sido uma grande discussão nos meios acadêmicos, porém, não há dúvida que teremos que passar por uma mudança cultural acadêmica. As maiores universidades do Brasil, como USP, UNICAMP and UNESP, estão inaugurando seus próprios repositórios que contém os dados dos pesquisadores das universidades. Será que os cientistas estão preparados para uma ciência que não visa a competição?

O preprint pode ser uma das chaves para a democratização da ciência. A interação e participação possibilitarão pesquisas científicas mais acessíveis, e, quem sabe, ajudar a diminuir o monopólio das editoras. Em consonância com esta tendência, a ABCS Health Sciences a partir de 2020 passa a aceitar manuscritos que foram depositados anteriormente como preprints, colaborando para a tão sonhada "Open Science". 


\section{REFERÊNCIAS}

1. Packer AL. ScielO e o futuro dos periódicos. Disponível em: https://blog.scielo.org/blog/2016/12/21/scielo-e-o-futuro-dosperiodicos/. Acesso em: 17 ago 2019.

2. Spinak E. O que é este tema dos preprints?. Disponível em: https://blog.scielo.org/blog/2016/11/22/o-que-e-este-tema-dospreprints/. Acesso em: 17 ago 2019.

3. eLife Early-Career Advisory Group. Webinar report: What's the deal with preprints? Disponivel em: https://elifesciences.org/insideelife/d4017493/webinar-report-what-s-the-deal-with-preprints. Acesso em: 01 nov 2019.

4. Melo M. O que é um preprint? Avaliable from: O que é um preprint? Avaliable from: https://marcoarmello.wordpress.com/2018/10/30/ preprint/. Cited: 2019 Nov 01.

5. Mudrak B. What are Preprints, and How Do They benefit authors? Avaliable from: What are Preprints, and How Do They benefit authors? Avaliable from: https://www.aje.com/arc/benefits-ofpreprints-for-researchers/. Cited: 2019 Nov 01.

6. Bourne PE, Polka JK, Vale RD, Kiley R. Ten simple rules to consider regarding preprint submission. PLoS Comput Biol. 2017;13(5):e1005473.

https://doi.org/10.1371/journal.pcbi.1005473 